\title{
En transición: Las primeras road movies del cine español (1975-1978)
}

\author{
Santiago García Ochoa \\ IES Manuel Chamoso Lamas
}

RESUMEN:

La road movie es un género muy ligado a la cultura norteamericana que surge a finales de los 60 y rápidamente se difunde por las cinematografías de todo el mundo. En el cine español su aparición no se produce hasta mediados de la década de los 70, coincidiendo con los primeros años de la transición a la democracia (1975-1978) y la ideologización de los géneros populares, debido al retraso industrial y de las infraestructuras, pero fundamentalmente por la inexistencia de una imagen de la carretera como espacio de búsqueda y de reafirmación individual. En este artículo se analizan las cuatro películas fundacionales del cine español on the road.

\section{PALABRAS CLAVE:}

road movie, cine español, iJo, papá!, El alijo, El puente, Vámonos, Bárbara

\section{ABSTRACT:}

The road movie is a genre closely linked to American culture that emerged in the late 1960s and it is quickly diffused around the world. Its appearance in Spanish cinema did not grow until the mid-1970s, coinciding with the first years of the transition to democracy and the ideologization of popular genres, due to industrial and infrastructure delays but mainly due to the lack of an image of the road as a space for individual search and reaffirmation. This article analyzes the four foundational films of Spanish cinema on the road.

\section{KEYWORDS:}

road movie, Spanish Cinema, iJo, papá!, The Stash, Foul Play, Let's Go, Bárbara 


\section{Introducción}

En los últimos años el interés académico por las road movies ha ido aumentando de forma exponencial, presentándose como un fenómeno que afecta a cinematografías de todo el mundo. Casi todos los especialistas sitúan el nacimiento de la road movie en EE UU a finales de la década de los 60, dentro del periodo conocido como New Hollywood (1967-1975), bajo la influencia de los "nuevos cines" europeos ${ }^{1}$. Según Anne Hurault-Paupe "(...) the expression «road picture" proper emerged in September 1970, in critical discourses produced on Bob Rafelson's Five Easy Pieces [Mi vida es mi vida, 1970]"2. Monte Hellman emplea este mismo término para referirse a su película Two Lane Blacktop (Carretera asfaltada en dos direcciones, 1971) en diversas entrevistas concedidas a revistas europeas. Thomas Elsaesser, en su célebre artículo de 1975 sobre los héroes desmotivados del nuevo cine americano, invadidos por lo que él llama el "pathos del fracaso", habla ya de "road movies" . Pero la difusión del término "road movie" no se producirá hasta la segunda mitad de los 70, en paralelo a la difusión y la influencia internacional de las películas de New Hollywood, vinculada especialmente a la figura del cineasta germano Win Wenders, que fascinado por la cultura norteamericana, realiza su "trilogía de la carretera": Alice in den Städten (Alicia en las ciudades, 1974), Falsche Bewegung (Falso movimiento, 1975) y Im Lauf der Zeit (En el curso del tiempo, 1976) y funda su productora Road Movies Filmproduction (posteriormente rebautizada Neue Road Movies) en 1976 para acometer su siguiente proyecto, Der amerikanische Freund (El amigo americano, 1977). En España el anglicismo "road movie" no se emplea hasta finales de los 70 , siendo uno de sus principales introductores Antonio Wein-

Sobre el sustrato de una serie de elementos típicamente norteamericanos, como el espíritu fundacional de la extensión de la frontera, la literatura de Mark Twain, el western, la "Highway Culture" posterior a la II Guerra Mundial o la contracultura, a partir de la novela $O n$ the Road (1957) de Jack Kerouac.

HURAULT-PAUPE, Anne, "The paradoxes of cinematic movement: is the road movie a static genre?", en $\mathrm{Mi}$ randa, $\mathrm{n}^{\circ} 10,2014$, p. 3.

3 ELSAESSER, Thomas, "The Pathos of Failure: Notes on the Unmotivated Hero", en Monogram, n 6, October 1975, pp. 13-19. En 1973 Joseph Strick había realizado en EE UU una película de camioneros titulada Road movie. richter, con sus libros El nuevo cine americano (Zero, Bilbao, 1979) y Win Wenders (JC, Madrid 1981) ${ }^{4}$.

En cualquier caso, la definición de las coordenadas del género que nos ocupa en el ámbito académico se produjo mucho más tardíamente, entre finales del siglo XX y principios del siglo XXI, con la obra A Cinema Without Walls: Movies and Culture after Vietnam (Rutgers University, New Brunswick, 1991) ${ }^{5}$ del profesor norteamericano Timothy Corrigan como primer eslabón. Yo mismo he dedicado un par de artículos al tema ${ }^{6}$ por lo que a continuación me limitaré sólo a resumir las características de la road movie sin descuidar la naturaleza dual, semántica y sintáctica, que debe poseer todo corpus genérico.

La estructura narrativa de estas películas gira en torno al viaje por carretera, y en ella se suelen distinguir cuatro etapas: breve presentación del entorno del protagonista, que le resulta opresivo; abandono de ese entorno en busca de nuevas ilusiones y perspectivas; confrontación entre el protagonista, los lugares que va visitando y los personajes con los que se encuentra (de todo extrae enseñanzas); el protagonista contempla el mundo de manera distinta, su balance puede ser positivo (ha conseguido lo que busca y concluye el viaje), negativo (no lo ha conseguido y prosigue el viaje), o incluso nulo (ha descubierto la imposibilidad de lograrlo) ${ }^{7}$. En realidad la meta del viaje termina resultando irrelevante y en

4 Antes se habían empleado otros términos como "película de itinerancia" o "film itinerate", aunque con escasa profusión.

5 El autor dedica a la road movie el capítulo cinco: "Genre, Gender and Hysteria: The Road movie in Outer Space" (pp. 137-160).

6 A saber: "Algunas notas sobre la aplicación de la categoría de género cinematográfico a la Road Movie", en Liño, no 15, 2009, pp. 187-196 y “En tránsito: Un recorrido por la road movie norteamericana”, en Signa, vol. 27, 2018, pp. 419-438.

7 Cfr. FRASCA, Giampiero, ROAD MOVIE. Immaginario, genesi, struttura e forma del cinema americano on the road, UTET, Torino, 2001, p. 55. Como indica el autor se trata de la estructura de la novela picaresca española, cita Lazarillo de Tormes (1554), Guzmán de Alfarache (1599) y Estebanillo González (1646); aunque existe una diferencia fundamental entre el pícaro y el viajero de la road movie, ya que "(...) mentre quest'ultimo sfugge totalmente dall'ambiente sociale originario per percorrerlo ai margini, su quel limite che genera l'illusione della ricerca della totalle libertà, lo scaltro furfante spagnolo opera con la sua furbizia e la sua sfrontatezza nelle pieghe di quella società decadente che osserva con distaccata ed ironica partecipazione" (p. 56). 
muchos casos éste concluye con la muerte de los protagonistas: Bonnie and Clyde (Bonnie y Clyde, Arthur Penn, 1967), Easy Rider (Easy Rider. En busca de mi destino, Dennis Hopper, 1969), Vanishing Point (Punto limite: cero, Richard C. Sarafian, 1971) o Thelma \& Louise (Ridley Sco$\mathrm{tt}$, 1991). Los personajes de las road movies casi siempre son hombres, o como mucho parejas heterosexuales (Bonnie and Clyde), hasta Thelma Ct Louise ${ }^{8}$. En muy escasas ocasiones aparecen mujeres viajando solas en busca de su destino antes de 1991, y cuando lo hacen sus intentos emancipadores chocan con los hombres que se encuentran en su camino, como sucede en The Rain People (Llueve sobre mi corazón, Francis Ford Coppola, 1969), Wanda (Barbara Loden, 1970) y Alice Doesn't Live Here Anymore (Alicia ya no vive aquí, Martin Scorsese, 1974). Por último, el predominio del rodaje en escenarios naturales con equipos ligeros y camera car permite filmar desde vehículos en movimiento por la carretera e incluso la evolución de los personajes en el interior de sus automóviles, así como afrontar la realidad social con un estilo cercano al documental.

Frecuentemente se ha recurrido a los estudios transnacionales para analizar la presencia de la road movie fuera de EE UU. En un artículo reciente defiendo la existencia de tres posibles vías de trabajo desde esta perspectiva: la primera se centra en las fricciones entre lo nacional y lo transnacional, la segunda se interesa por la posibilidad de fijar modelos regionales de road movie (paneuropeo, nórdico), la tercera tiene en cuenta la importancia que adquieren el exilio y la diáspora en los cines periféricos, y cómo el recurso a la road movie facilita la aceptación internacional de unas películas que construyen una identidad nacional ajena a la europea ${ }^{9}$.

El estudio de la road movie en el cine español, claramente enmarcado dentro de la primera de las vías descritas, obliga a plantearse preguntas como: ¿cuáles fueron los condicionantes históricos e industriales que acompañaron la aparición del género?, ¿cómo se encarnan los

8 A partir de la década de los 90 el hombre blanco joven heterosexual (american male) se verá desplazado por todo tipo de alternativas sexuales y raciales (mujeres, gays, transexuales, indios, afroamericanos), enfermos, discapacitados y ancianos.

9 GARCÍA OCHOA, Santiago, "La road movie como modelo transnacional y su presencia en el cine español: marco metodológico y principales aportaciones", en Boletín de Arte, $\mathrm{n}^{\circ}$ 37, 2016, pp. 80-82. elementos del modelo canónico norteamericano en las películas españolas? Estas cuestiones han sido respondidas sólo parcialmente en la escasa bibliografía existente ${ }^{10}$, cuya aportación más significativa hasta la fecha ha sido el libro de Jorge Pérez Cultural Roundabouts: Spanish Film and Novel on the Road (Bucknell University Press, Lewisburg, 2011), que como su título indica no se ciñe en exclusiva a las películas, y estudia el road genre también en la literatura. En un artículo reciente intenté abordar el tema desde una perspectiva diacrónica diferenciando tres fases en la historia del cine español on the road:

“a) Carreteras franquistas (1955-1975). Coincide con el final de la autarquía y el segundo franquismo, y permite constatar la incompatibilidad de la imagen de la carretera como espacio de búsqueda con la dictadura, aunque durante los años 50 se percibe la influencia de dos de los géneros del cine norteamericano que, según Frasca, prefiguran la road movie: la comedia sofisticada y el cine negro.

b) Carreteras hacia la democracia (19751982). Coincide con la Transición y es el periodo en el que aparecen las primeras road movies: ¡Jo, papá! (Jaime de Armiñán, 1975), El alijo (Ángel del Pozo, 1976), El puente (Juan Antonio Bardem, 1977), Vámonos, Bárbara (Cecilia Bartolomé, 1978), A contratiempo (Óscar Ladoire, 1981) y Corridas de alegría (Gonzalo García Pelayo, 1981).

c) Carreteras democráticas (1982-a la actualidad). Coincide con la España democrática y comprende la evolución del cine español on the road, que experimenta su boom a partir de la segunda mitad de los 90 y se desarrolla en diferentes vías temáticas o subgéneros” ${ }^{11}$.

En este trabajo intentaremos desgranar los condicionantes históricos e industriales que acompañaron la aparición de la road movie en el cine español y cómo éstos se encarnaron en cuatro películas fundacionales, dentro de la fase "Carreteras hacia la democracia" (19751982): ¡Jo, papá!, El alijo, El puente y Vámonos, Bárbara.

10 Un estado de la cuestión puede verse en GARCÍA OCHOA, Santiago, "La road movie como modelo...", opus cit., pp. 83-85.

11 GARCÍA OCHOA, Santiago, "Viajes con sentido: Notas para una historia del cine español on the road", en Latente, $\mathrm{n}^{\circ} 16,2018$, p. 144. 


\section{Una coyuntura favorable (1975-1978)}

La irrupción de la road movie en el cine español se produce en un momento en el que los géneros populares (peplum, spaghetti western, cine de terror, ciencia-ficción, aventuras, thriller, comedia sexy, etc.), en pleno auge desde la década de los 60 , se estaban viendo obligados a hacerse eco de los trascendentales fenómenos que afectaban a la realidad española desde 1973 (asesinato de Carrero Blanco, declive y muerte de Franco, inicio de la Transición, crisis económica) para poder seguir captando la atención de los espectadores:

"Así, dos comedietas sexy-ibéricas producidas ese año [1975], Tres suecas para tres Rodríguez de Lazaga, y La dudosa virilidad de Cristóbal [de Juan Bosch], que sólo un año antes se hubieran estrenado sin mayor problema, tuvieron que esperar hasta 1977 para llegar al público: los tiempos, decididamente, estaban cambiando" ${ }^{12}$.

Dentro de esta coyuntura de "ideologización de los géneros populares”, por emplear la terminología de Hernández Ruiz y Pérez Rubio ${ }^{13}$, la metáfora de la movilidad asociada al cambio político y social encontró su articulación en un nuevo modelo made in USA: la road movie, lo cual ejemplifica a la perfección el carácter flexible de este género.

Una serie de condicionantes históricos justifican la demora del nacimiento del cine español on the road hasta la segunda mitad de la década de los 70, coincidiendo con el núcleo duro de la Transición (1975-1978). El retraso industrial (la producción de automóviles supera por primera vez a la demanda en 1966 14 y la precariedad de las infraestructuras (el Programa Nacional de Autopistas Españolas se redacta en 1967)

12 TORREIR0, Casimiro, "Del tardofranquismo a la democracia (1969-1982)", en Historia del cine español, Cátedra, Madrid, 1995, p. 366.

13 Cfr. HERNÁNDEZ RUIZ, Javier y PÉREZ RUBIO, Pablo, Voces en la niebla. El cine durante la Transición española (1973-1982), Paidós, Barcelona, 2004.

14 Los españoles tuvieron acceso a la motocicleta antes que al automóvil: entre 1953 y 1963 la matriculación de motocicletas superó ampliamente a la de turismos, y en la década de los 50 alcanzó las 956.942 unidades, el $60 \%$ del total de vehículos matriculados. Cfr. HERNÁNDEZ MARCO, José Luis, "La oferta automovilística en España antes del «SEAT 600»: 1906-1957", en Economía Industrial, no 307, enero-febrero de 1996, p. 143. propiciaron una motorización muy tardía de las clases medias, o lo que es lo mismo, que durante bastante tiempo el coche funcionase, casi en exclusiva, como símbolo del estatus social, $\mathrm{y}$ muchos continuasen viajando en tren o en autobús ${ }^{15}$. Las primeras road movies norteamericanas llegaron a las pantallas españolas con retraso ${ }^{16}$ y la mayor parte de las veces pasaron desapercibidas para el gran público, situación lamentada por un importante sector de la crítica, muy interesado en este nuevo cine americano de influencia europea: The Rain People y Badlands (Malas tierras, Terrence Malick, 1973) ganaron la Concha de Oro del Festival de San Sebastián en 1969 y 1974 respectivamente. Easy rider, premiada en Cannes como mejor ópera prima en 1969, se estrenó en el cine Infantas de Madrid el 28 de noviembre de 1975 en versión original subtitulada ${ }^{17}$.

Como ha demostrado Jorge Pérez ${ }^{18}$, las metáforas asociadas al viaje aparecen con cierta frecuencia en las obras que estudian la Transición. En ellas, la movilidad se presenta como algo positivo, asociada a la liberación y al progreso, en clara contraposición al estancamiento de la dictadura franquista. En cualquier caso, la Transición no fue un proceso rectilíneo y las road movies españolas “(...) represents a mobile country where mobility does not take place along a smooth and straightforward path, but rather by taking detours, encountering unexpected bumps, and sometimes making (un)necessary stops and U-turns" ${ }^{19}$.

El recurso al camino o al viaje en clave metafórica es una constante en las manifestaciones escritas y visuales del periodo 1975-1978, cubriendo todo el arco ideológico. Citaremos

15 Los viajes en motocicleta resultaban mucho más incómodos si había que cubrir largas distancias e inviables si eran varios los que viajaban o se quería llevar equipaje. Como prueba de ello se puede ver el documental en color del NODO Veinte provincias en Vespa (1962) sobre la carrera anual que recorría España de sur a norte y concluía en Madrid cubriendo más de 3.000 kilómetros en siete días.

16 El caso más extremo fue el de Two Lane Blacktop, que no se proyectó hasta 1980.

17 La película había obtenido el segundo trofeo "Caracola-Alcance 74" en Cádiz (38\% de los votos del público). En el fin de semana posterior a su estreno ya aparecía en Blanco y Negro (6 de diciembre de 1975, p. 78) como una de las cintas mejor valoradas (8 sobre 10).

18 PÉREZ, Jorge, Cultural Roundabouts: Spanish Film and Novel on the Road, Bucknell University Press, Lewisburg, 2011, pp. 36-38.

19 PÉREZ, Jorge, Cultural Roundabouts..., opus cit., p. 36. 
sólo tres ejemplos como muestra de ello. El primero es el comienzo del artículo "El gobierno, ¿de quién es?” publicado por Emilio Romero en $A B C$ el 22 de abril de 1976 (p. 3):

"En el camino que hemos emprendido hacia la democracia conviene aclarar algunas cosas: la principal es saber a dónde vamos, con quien y para qué. Decir que vamos hacia una democracia es como señalarnos que nos dirigimos hacia el Sur. Es una orientación, pero no es un camino, ni un destino. La gente anda desorientada y sorprendida”.

El segundo, la caricatura de Máximo que apareció en El País el 9 de julio de 1977. En ella los españoles recorren un camino jalonado con los hitos del largo proceso de la transición a la democracia, que “(...) revela al tiempo una esperanza y una impaciencia por los retrasos en la consecución de ese objetivo"20 (Fig. 1).

El tercero y último es la canción "Hijos del agobio", que da título al disco del grupo de rock andaluz Triana publicado en $1977^{21}$, y a la que se le puede “(...) atribuir con rigor la condición de himno generacional y de alegato poético de tipo romántico"22:

"Dormidos al tiempo y al amor,

un largo camino y sin ilusión

que hay que recorrer,

que hay que maldecir.

Hijos del agobio y del dolor,

cien fuerzas que inundan el corazón

separan de ti,

(me) separan de ti.

Quiero sentir algo que me huela a vida, que mi sangre corra loca de pasión, descubrir la música que hay en la risa,

la luz profunda y el amor.

Despiertos al tiempo y al amor,

un largo camino y con ilusión

que hay que recorrer,

desde ahora hasta el fin.

Hijos del agobio y del dolor".

20 MELÉNDEZ MALAVÉ, Natalia, El humor gráfico en el diario "El País" durante la transición política española (1976-1978) (tesis doctoral), Universidad de Málaga, Málaga, 2005, p. 316.

21 El LP fue producido por Gonzalo García-Pelayo unos años antes de dirigir Corridas de alegría (1981), una de las road movies más emblemáticas de la Transición.

22 LABRADOR MÉNDEZ, Germán, Poéticas e imaginarios de la transición española: campo, discursos, fracturas (tesis doctoral), Universidad de Salamanca, Salamanca, 2008, p. 487.

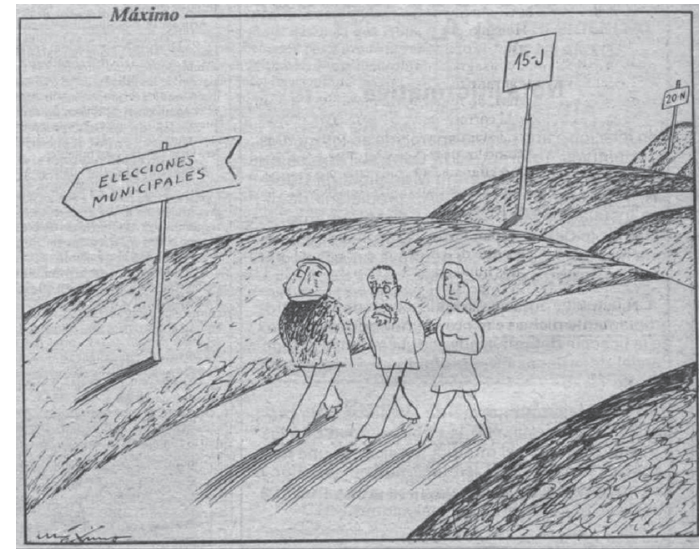

119

Fig. 1. Los españoles recorren el largo camino hacia la democracia en una caricatura de Máximo (El País, 9 de julio de 1977).

\section{Las primeras road movies del cine español}

En las líneas que siguen abordamos la fase fundacional del género que, como ya hemos adelantado, coincide con el núcleo duro de la Transición (1975-1978): de iJo, papá!, estrenada tras la muerte de Franco, el 18 de diciembre de 1975, quince días después de que Torcuato Fernández Miranda jurara su cargo como presidente de las Cortes, a Vámonos, Bárbara, estrenada al año siguiente de las primeras elecciones, el 18 de octubre de 1978, trece días antes de la aprobación por las Cortes de la Constitución de $1978^{23}$. Quedan fuera de este trabajo $A$ contratiempo y Corridas de alegria, road movies emblemáticas pero que poseen un carácter diferente a las cuatro que aquí estudiaremos, fruto de la coyuntura posterior y del espíritu del "desencanto"24, que se materializa en sendas historias sobre el fracaso de una relación amorosa.

¡Jo, papá!, rodada antes de la muerte de Franco y estrenada después ${ }^{25}$, recrea las aven-

23 Con bastante retraso, ya que su rodaje había finalizado en octubre del año anterior (Archivo General de la Administración, Sección Cultura, Exp. 36/05264).

24 La estabilización de la vida política tras la aprobación en referéndum de la Constitución de 1978 provocó un sentimiento de desengaño en aquellos rupturistas que anhelaban la revolución total. El término "desencanto" se empleó “(...) para denominar tanto el sentir de una generación cansada tras intensos años de «bombardeo político", como el clima de pasotismo y desconfianza de jóvenes antifranquistas, que ven con escepticismo la burocratización de promesas no cumplidas". Cfr. ARDÁNAZ, Natalia, "La Transición política española en el cine (1973-1982)”, Comunicación y sociedad, vol. XI, $\mathrm{n}^{\circ} 2$, 1998, pp. 157-158.

25 Las dos primeras versiones del guión fueron desestimadas por la censura, y cuando se terminó el film, 
turas de Enrique Seoane (Antonio Ferrandis), un comerciante vigués nostálgico de la guerra civil que, aprovechando las vacaciones de Semana Santa, embarca a su mujer Alicia (Amparo Soler Leal) y sus dos hijas: Pilar (Ana Belén), de 23 años, y Carmen (Carmen Armiñán), todavía una niña, en un viaje hasta Vinaroz, como hiciera en la primavera de 1938 con las tropas franquistas. Es este un punto de partida que contraviene el de las primeras road movies de New Hollywood, en las que los protagonistas suelen ser rebeldes o inadaptados. Además, las familias on the road no suelen aparecer en el cine norteamericano hasta comienzos del siglo $\mathrm{XXI}^{26}$.

La atención del film se centra en determinados puntos geográficos, cargados de significado para el protagonista, elegidos para ir enhebrando sus recuerdos de la guerra civil. La familia asume la experiencia de forma muy distinta. Enrique intenta recuperar las vivencias del conflicto bélico, aunque su entusiasmo choque una y otra vez con unos escenarios y unos personajes difuminados, cambiados por el tiempo (el padre Comesaña [Eduardo Calvo], su capellán durante la guerra, ahora está casado y tiene hijos). Armiñán se ensaña hasta la saciedad con un personaje situado fuera de contexto, ridiculizándolo constantemente. Por ejemplo, cuando acampan donde Enrique abrió fuego por primera vez, la música y los tiros con los que se acompaña su descripción de los hechos se ven sustituidos en el siguiente plano por los ronquidos y la tos del protagonista, que impiden dormir a su mujer. Alicia, por su parte, se debate entre la posibilidad de iniciar una aventura con Julio (Fernando Fernán-Gómez), su primer novio, con el que se ha reencontrado recientemente en $\mathrm{Vigo}^{27}$, y la fidelidad a unos

éste fue nuevamente rechazado. El director cuenta que el funcionario de turno le dijo textualmente: "No te hagas ilusiones, mientras viva la momia de El Pardo esta película no se estrena”. ARMIÑÁN, Jaime, "Del 75 al 85: Las difíciles condiciones", en La cultura española en el posfranquismo. Diez años de cine, cultura y literatura en España (1975-1985), Playor, Madrid, 1988, pp. 33-34.

26 Cfr. GARCÍA OCHOA, Santiago, “En tránsito...”, opus cit., pp. 433-434.

27 Aunque nada se dice sobre la causa que lo llevó a ausentarse durante la guerra civil, todo hace suponer que su situación es la misma que la del viejo exiliado republicano (también interpretado por Fernán-Gómez) que vuelve a casa durante los últimos años de la dictadura en El amor del capitán Brando (1974), la anterior película de Armiñán. principios: cuando la ilusión se rompe y comprende que es demasiado tarde para echar la vista atrás, hará el amor con su marido (la noche antes de llegar a Vinaroz). Para Pilar, la inadaptada, el viaje es hacia el futuro: si Enrique evita Teruel, lugar donde encontraron la muerte tantos compañeros, su hija se escapa para reunirse allí con Carlos (José María Flotats), un joven locutor al que conoció en Oviedo; y vuelve más libre, resuelta a afrontar su propio destino. En cuanto a Carmen, asiste indiferente a los acontecimientos pues es demasiado pequeña para valorarlos.

La película se cierra en la playa. Enrique se baja del coche y, apoyado en el capó, enmarcado por la luna delantera, explica a su familia el encuentro de los dos ejércitos. Después se vuelve y se dirige lentamente al Mediterráneo. La cámara toma desde atrás a los ocupantes del coche (Alicia, Pilar y Carmen), como si se tratara de los espectadores que asisten a una proyección cinematográfica. Con ello Enrique se convierte en un personaje irreal y su relato en pura ficción (Fig. 2). Alicia recomienda a Pilar que se vaya, que los deje, que no cometa su mismo error. La joven, harta de contemplar el pasado, se marcha a iniciar una nueva vida. Ya solas y fuera del coche, Alicia y Carmen contemplan, resignada la una, con fastidio la otra (exclama “¡Jo!”), cómo Enrique se sumerge en las aguas del pasado.

El alijo, adaptación de la novela corta homónima de Ramón Solís publicada en 1965, se sitúa en el terreno del thriller y el género criminal (contrabando de tabaco, traslado de emigrantes ilegales), aunque posee algunos episodios cómicos, como el del árbitro de fútbol o el del borracho que le atribuye cualidades humanas a los supuestos borregos del camión.

El film está estructurado en torno al desplazamiento por carretera y el encuentro con diversos personajes de la pareja masculina (male "buddy" couple) de camioneros formada por el veterano Paco (Fernando Sancho) y el joven $\mathrm{Cu}$ rro (Juan Luis Galiardo) ${ }^{28}$. Comienza con la llegada a la playa de un alijo de tabaco que Paco y

\footnotetext{
Un universo similar había aparecido ya en Los camioneros, serie de TVE de trece episodios dirigida por Mario Camus (emitida entre noviembre de 1973 y febrero de 1974). En ella, Sancho Gracia interpreta a Paco, un transportista madrileño que viaja a lo largo y ancho de la geografía española, siempre con un compañero diferente. Paco encarna el estereotipo del camionero ligón y los roles que se muestran en la serie son muy
} 


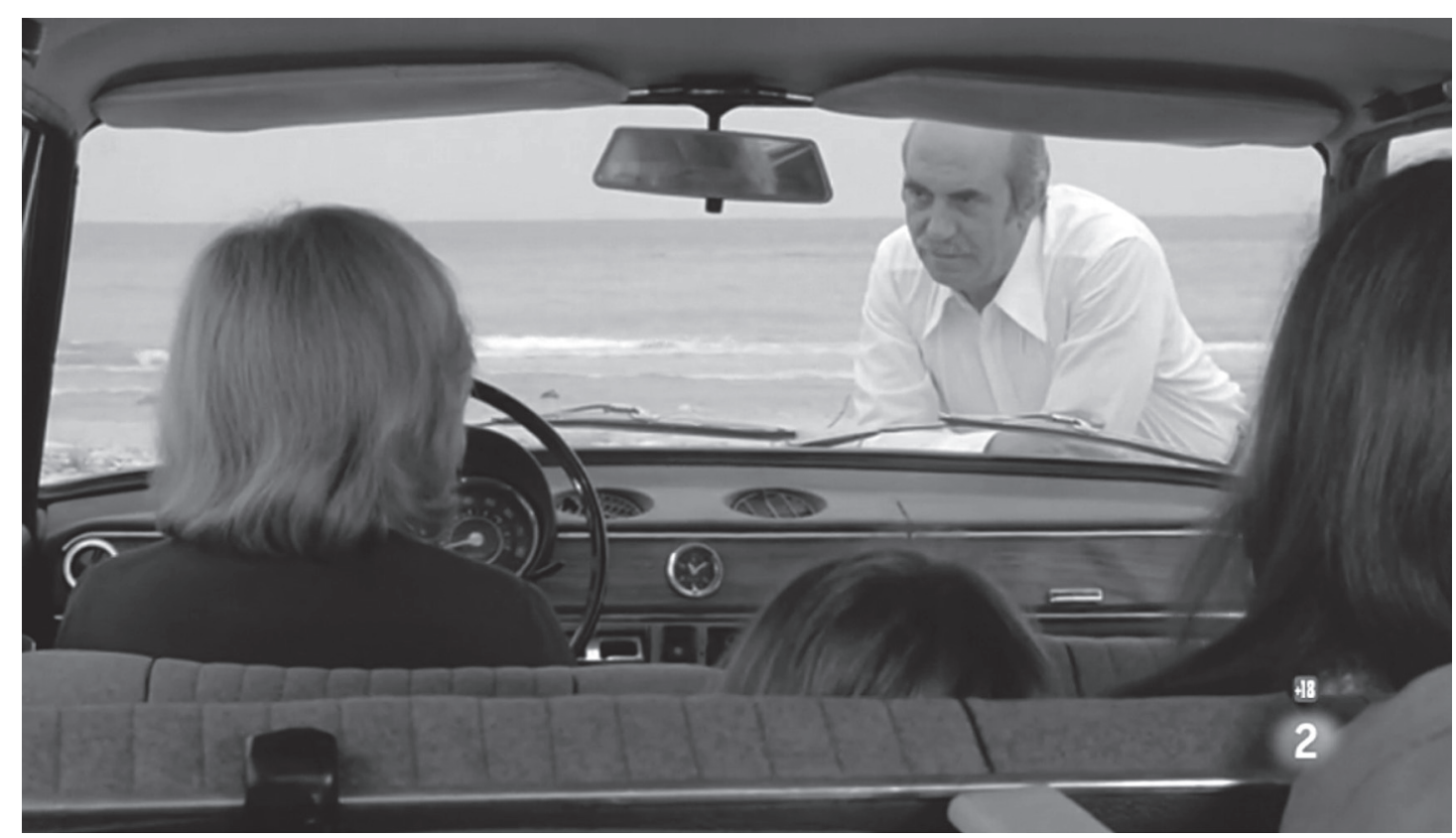

Fig. 2. Alicia y sus dos hijas atentas al relato de Enrique en jJo, papá!.

Curro llevan a Madrid. El siguiente encargo son un grupo emigrantes portugueses sin papeles que quieren llegar hasta Francia, cargamento especial que les reportará una suculenta paga ${ }^{29}$. Este viaje, que se convierte en la trama principal de la narración, no aparece en la novela de Solís, consagrada en exclusiva al contrabando de tabaco. La introducción del elemento humano, un grupo de personas de diferentes sexos y edades que viajan en difíciles condiciones (escondidos entre ovejas) a la busca de una vida mejor propicia el estrechamiento de la relación entre los dos camioneros, cuyo futuro también está en el aire. Éstos irán experimentando además un progresivo cambio de actitud respecto a las personas que transportan: si inicialmente muestran un cierto distanciamiento (bromean sobre su situación), poco a poco se van convenciendo de sus dificultades (les dan agua en un cubo, luego una garrafa de vino y pan) hasta quedar profundamente concienciados (primero Paco, al descubrir al anciano muerto; finalmente los dos cuando, al término del viaje, se ente-

representativos de la "buena moral" franquista del momento.

29 La emigración clandestina de portugueses a Francia adquirió una gran relevancia entre los años 60 y 70, superando en algunos periodos a la emigración legal. Muchos emigrantes tuvieron un desenlace trágico. En cualquier caso, se trata de un fenómeno fuertemente censurado en los medios de comunicación de la época sobre el que no existen muchos datos fiables. ran del difícil camino que aún deben recorrer a pie para llegar a Francia).

Tras la experiencia, Paco y Curro ven el mundo de una manera distinta: están decididos a dejar el contrabando. Curro propone coger una carga hasta Madrid y otra hasta Cáceres (lugar de entrega del camión) para no ir de vacío, Paco accede. El joven llama por teléfono a su novia y le pide matrimonio, luego propone a su colega que compren el camión para formar una sociedad y que sea su padrino de bodas. El accidente de la pareja que los contrató (y los acompañaba delante en un coche) parece tirar al traste con todo (todavía no habían cobrado $)^{30}$, pero Paco se ofrece a invertir sus ahorros en el negocio. La película se cierra en ruta, con la broma de Curro que comenta: "Oye, Paco, en cuanto tengas otro negocio como este, tú me avisas, ¿eh?"; su colega contesta sorprendido: “¿Cómo?”; y los dos se ríen. Entonces se congela la imagen y aparecen los créditos (Fig. 3). Nuevamente nos encontramos con un cambio significativo con respecto a la novela, que tiene un final trágico: Curro se despista y un coche se les echa encima, entonces conduce el camión a la cuneta y salta en el último momento, sólo

\footnotetext{
30 En realidad el "señorito" (Manolo Zarzo) no tenía ninguna intención de pagarles, y el coche se sale de la carretera cuando intenta saltar con todo el dinero para vengarse de su jefa y pareja (Helga Liné), que le había puesto los cuernos en el pueblo con Curro.
} 


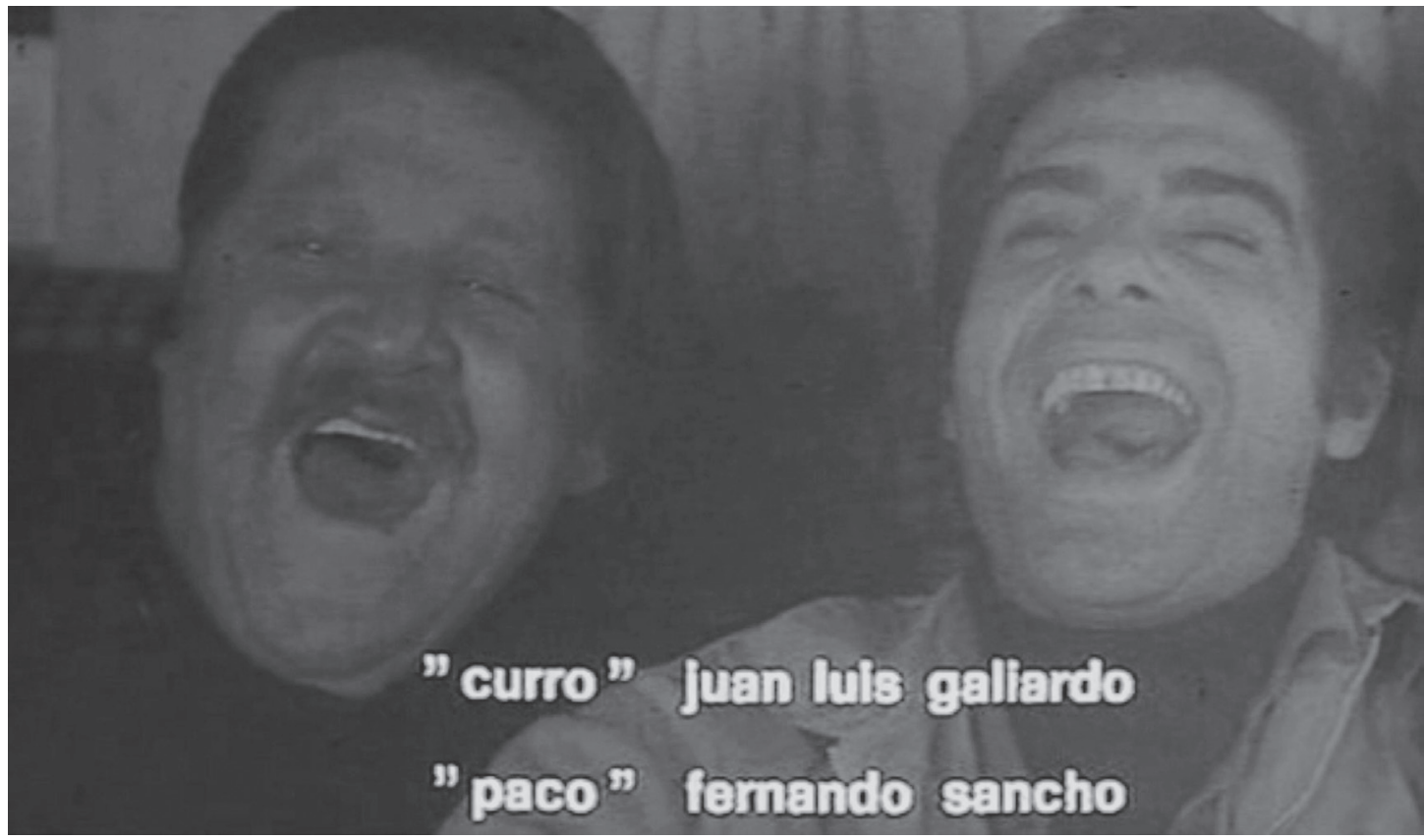

Fig. 3. Curro y Paco riendo en el último plano de El alijo.

él se salva del fatal accidente (desenlace que parece presagiar el de algunas de las más célebres road movies, como Bonnie and Clyde, Easy Rider o Vanishing Point).

Fue el propio Solís, autor del guión, el responsable de la "puesta al día" de su novela, convirtiéndola en un relato muy acorde con las transformaciones que se avecinaban (el permiso de rodaje de El alijo es del 17 de noviembre de 1975, tres días antes de la muerte de Franco ${ }^{31}$ ).

El puente, habitualmente etiquetada como la primera road movie del cine español ${ }^{32}$, es sin duda la película que más y mejor se adapta al modelo norteamericano de las aquí abordadas. De ello se hicieron eco sólo algunas de las críticas publicadas con ocasión de su estreno (a pesar de que casi todas insistieron en señalar la importancia concedida al viaje y los encuentros como factor de cambio en la evolución del protagonista $\left.{ }^{33}\right)$ : Antonio Colón escribió que “(...)

31 Archivo General de la Administración, Sección Cultura, Exp. 36/05199.

32 Cfr. POHL, Burkhard, "Rutas transnacionales: la road movie en el cine español”, en Hispanic Research Journal, vol. 8, n 1, 2007, p. 56 y PÉREZ, Jorge, Cultural Roundabouts..., opus cit., p. 36.

33 Presente ya en varias de las frases promocionales de la película, como " "Sancho Panza" cruza "El puente» y encuentra a D. Quijote", "Viaje con Alfredo Landa en la mejor dirección: "El puente», de J. A. Bardem" o la técnica recuerda en algunos momentos algunas películas de estos últimos años, como el "Espantapájaros» [Scarecrow, Jerry Schatzberg, 1973], análisis de realidades sociales, un procedimiento de transformación a través de un viaje catártico" ${ }^{34}$; José María Latorre la definió como “(...) una paráfrasis de La escapada [Il sorpasso, Dino Risi, 1962] (ese sonreír-para-mejor-meditar) y Easy Rider (la entraña de un país vista a la altura de la moto)", denominándola más adelante "film itinerante" 35 ; Carlos F. Heredero, por su parte, consideró que recurría a “(...) una estructura narrativa que representa, en esquema muy extractado, el cuerpo de una cierta forma de narrativa clásica americana, de sobradamente demostrada eficacia y en torno a la cual se podría agrupar un número considerable de obras importantes" y también la catalogó como un "filme de "itinerario"” aunque criticó el uso abusivo de los planos del protagonista por la carretera “(...) que terminan dando lugar a una discutible y machacona estética seudo-«Easy Rider" (...)”36.

"Las aventuras de Alfredo Landa entre las gentes y las tierras de un país desconocido: el nuestro".

34 COLÓN, Antonio, "El puente", $A B C$ (edición Andalucía), 1 de marzo de 1977, p. 39.

35 LATORRE, José María, “El puente de Juan Antonio Bardem”, Dirigido por..., nº 42, marzo de 1977, p. 40.

36 HEREDERO, Carlos F., "El puente. Aventura del motorista fantástico”, Cinema 2002, n 27 , mayo de 1977 , 
En cualquier caso no debemos olvidar que el film de Bardem parte de un texto literario de las mismas características que El alijo: la novela corta Solo de moto (1967) de Daniel Sueiro, representante, al igual que Solís, de la generación del medio siglo (autores que comienzan a publicar en los 50) y cultivador como aquel de la novela social ${ }^{37}$. Sueiro recrea la aventura de un inconformista mecánico que pretende viajar a Torremolinos en una Ducati 48 "Sport" a una media de $60 \mathrm{~km} / \mathrm{h}$ con el objetivo de "tirarse" a unas suecas saliendo de Madrid el sábado a las cinco de la tarde para estar de vuelta el lunes a primera hora en el taller. Los guionistas (Juan Antonio Bardem, Javier Palmero y el propio Sueiro) sustituyeron la Ducati por una Montesa Impala que superaba los 100 y alargaron el periodo de tiempo añadiéndole el lunes, diluyéndose con ello el carácter absurdo y nihilista del relato: “(...) monólogo itinerante de un doblemente ridículo Quijote de la motocicleta por el patente desequilibrio entre lo que es y lo que pretende ser, entre sus proyectos y sus posibilidades (...)" 38 .

El protagonista ni siquiera llega a pisar Torremolinos (en la película por lo menos le da tiempo a fumarse un pitillo en la playa), apenas entrevé el mar (a pocos kilómetros de Málaga) tiene que darse la vuelta para Madrid. Bardem, Palmero y Sueiro también multiplicaron los encuentros de Juan (Alfredo Landa) para posibilitar su toma de conciencia, aspecto totalmente ausente de la novela (pero imprescindible para Bardem): para ello tomaron algunos otros relatos de Sueiro incluidos en El cuidado de las manos (recopilación publicada en 1974 que recoge Solo de moto), el que da título al conjunto y Cambio de rasante, y fundamentalmente idearon otros nuevos acordes con la situación política y social de España en el verano de 1976 (cuando se rodó El puente) ${ }^{39}$. Desde el punto de

pp. 26-27.

37 Ambos títulos aparecieron publicados en la colección "La novela popular contemporánea inédita española" de la editorial Alfaguara.

38 VILLANUEVA, Darío, "Prólogo", en Cuentos completos, Alianza, Madrid, 1988, p. 16.

39 De la novela eliminaron algunos y mantuvieron intactos el de las extranjeras en el MG descapotable a la salida de Madrid y el de los emigrantes del pueblo de Juan que han hecho dinero en Alemania. Otros, como el del hombre que va andando dentro de un aro, el de la multa por ponerse en traje de baño y el de las americanas que lo recogen cuando pincha (hippies en la película) aparecen distorsionados. vista ideológico, estos episodios (que poseen, como el resto de la película, un marcado carácter didáctico) se pueden clasificar en tres tipos: los que critican a la burguesía (la humillación en el viñedo), los que reflejan los problemas de las clases populares (el paro del pueblo andaluz) y los protagonizados por grupos contraculturales que quieren transformar la sociedad (el grupo de teatro independiente) ${ }^{40}$.

El viaje en sí mismo adquiere un importante protagonismo en El puente y los planos de Juan conduciendo por la carretera mientras reflexiona o habla con su moto (la llama "Poderosa"41, como en la novela) se multiplican (Fig. 4), así como los del resto de los vehículos en los que en algún momento viaja el personaje, todos ellos rodados en exteriores, como corresponde a la estética de la road movie. Este uso y abuso del camera car, inhabitual en el cine español del momento ${ }^{42}$, quedó reflejado en el diario de rodaje de Bardem:

"A veces, la rueda delantera de la moto está a unos centímetros de la parte trasera del coche. ¡Y llegamos a ir hasta a $80 \mathrm{~km} / \mathrm{h}$ ! ¡Con el "zoom» de $250 \mathrm{~mm}$. podemos filmar, en movimiento, un gran primer plano de los ojos del "motorista fantástico».

Todo el equipo va encima del "camera-car", confortablemente instalado, y, de verdad, somos un espectáculo para los viajeros que usan la N-IV"43.

Durante el camino de regreso, de noche, Juan recuerda todo lo sucedido en el viaje de ida (encuentro consigo mismo), por eso el martes por la mañana en el taller cambia su negativa inicial a participar en el sindicato de la em-

40 CERÓN GÓMEZ, Juan Francisco, El cine de Juan Antonio Bardem, Universidad de Murcia, Murcia, 1998, p. 239.

${ }^{41}$ El mismo nombre de la moto que emplearon Ernesto Guevara y Alberto Granado en su mítico viaje por Latinoamérica.

42 Existe una película anterior a El puente que ya había explotado esta estética fruto del empleo del camera car e incluso de la introducción de la cámara dentro de un automóvil: Stress es tres tres (Carlos Saura, 1968), film representativo del "nuevo cine español" que se puede alinear con otros títulos europeos que alimentan el desarrollo de la road movie norteamericana, como Il sorpasso o Pierrot le fou (Pierrot el loco, Jean-Luc Godard, 1965).

43 BARDEM, Juan Antonio, "Parte de un diario", en El puente, SEDMAY, Madrid, 1977, p. 172. 


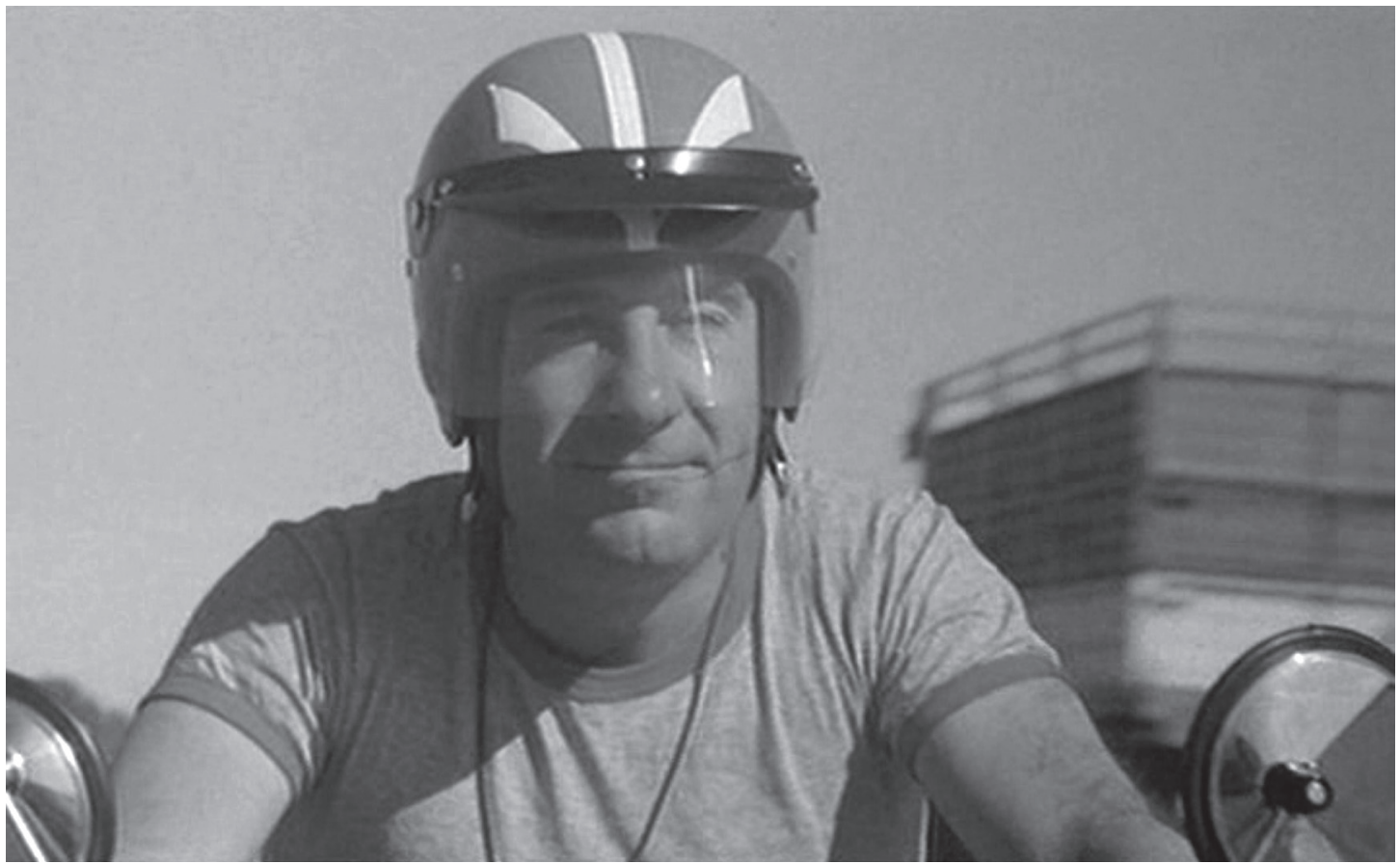

Fig. 4. Juan conduciendo por la carretera (filmado desde el camera car) en El puente.

presa por una emotiva llamada a la solidaridad dirigida a sus compañeros de trabajo:

"El caso de El puente (1976), de Bardem, es un claro ejemplo de la llamada a la concienciación política del español medio alienado por el franquismo, personaje encarnado por Alfredo Landa (en tanto actor y estereotipo narrativo). El texto del cartel publicitario del film de Bardem no deja resquicio a la interpretación: "Alfredo Landa, el pueblo; Bardem, la denuncia; El puente, la conciencia»" ${ }^{44}$.

El puente es el único de los cuatro títulos aquí estudiados en el que el viaje concluye en el punto de partida (se cierra el ciclo), presentando el cambio de actitud del personaje, fruto del aprendizaje adquirido, frente a la misma realidad que lo rodeaba antes de partir. Resulta muy ilustrativo fijarse en la primera y la última secuencia de la película (punto de partida y de llegada respectivamente) para comprobar esta evolución.

La película se abre con un plano detalle del airoso movimiento del culo de una mujer mien-

44 TRENZADO ROMERO, Manuel, Cultura de masas y cambio político: El cine español de la transición, Centro de Investigaciones Sociológicas, Madrid, 1999, p. 308. tras camina, a continuación se nos presenta su "delantera" y la cámara sube para mostrarnos su cara (degusta un polo). Un grupo de mecánicos la observan desde la puerta del taller, uno de ellos, un aprendiz, corre dentro gritando: "Maestro, maestro, que ya ha empezao el desfile". Sobre un plano medio de Alfredo Landa aparece sobreimpreso su nombre, y otro mecánico le espeta: "Juan, que hoy te lo pierdes". Esa es la presentación del protagonista, un viejo conocido para el espectador español del momento (Alfredo Landa, "el maestro de los culos y las tetas"). En el interior todos se preparan para salir pitando en cuanto den la una. Un padre de familia con el seiscientos hasta los topes le pide a Juan que le arregle el coche, pero él se niega. Dos empleados recuerdan que el domingo por la mañana en la parroquia hay asamblea para "lo del convenio", pero a Juan también le da lo mismo.

El martes, de regreso tras el "puente", Juan trabaja afanosamente en el motor de un coche hasta que se hace una herida. Va a los vestuarios a lavarse la mano, se queda pensativo, observa las pintadas de las paredes (tales como "amnistía", "unidad sindical", "libertad") y se mira en el espejo. Entonces acude a reunirse con los tres sindicalistas, que le ofrecen un cigarrillo, y conversan; la imagen se congela y aparece sobreimpreso "FIN". 
En realidad, El puente encierra toda una reflexión sobre la evolución del propio cine español (a la que ya nos hemos referido): al principio todo parece presagiar que Juan enseguida llegará a Torremolinos y la diégesis se desarrollará fundamentalmente allí, ligando con las suecas y demás (lo característico de una comedia sexy landista), pero en lugar de eso la película sólo es el viaje (de ida y vuelta), que provoca la toma de conciencia de Juan (nueva comedia ideologizada con mensaje).

Vámonos, Bárbara parte de la comedia de carga erótica (al borde de la clasificación "S") para reivindicar los derechos de la mujer, lastrados todavía por una realidad legal y social de raigambre franquista ${ }^{45}$. No en vano se trata de la ópera prima de Cecilia Bartolomé, la tercera mujer que había conseguido el diploma de dirección en la Escuela Oficial de Cinematografía, tras Josefina Molina y Pilar Miró, con una práctica de fin de carrera feminista muy combativa (Margarita y el lobo, 1969).

Ana (Amparo Soler Leal), una mujer de 38 años que trabaja en una agencia de publicidad de Barcelona, deja repentinamente a su marido (Carlos) y se marcha de vacaciones a la costa con su hija Bárbara (Cristina Álvarez) llevándose el Mercedes (su coche, un Ford Fiesta, se avería). Ana es una versión evolucionada (por el paso de los años y los cambios) de la Alicia de iJo, papá!: mientras en el film de Armiñán Amparo Soler Leal encarnaba a la característica esposa dependiente que se mantenía fiel a su marido a pesar del hastío, renunciando a la posibilidad de recuperar una relación de juventud; ahora, en el de Bartolomé, representa a la nueva mujer independiente que trabaja fuera del hogar y, harta de soportar ausencias y engaños, hace el amor con un compañero en el trabajo al que utiliza como objeto sexual para su desahogo (secuencia inicial de la película) ${ }^{46}$.

Ana y Bárbara realizan varios viajes por la costa, siempre con la sombra del marido/padre tras ellas, cuya presencia se manifiesta a través de una serie de personajes que actúan como los resortes de una legislación machista y anticuada. Mientras paran en la masía de la tía Remedios (Josefina Tapias), Carlos envía a su sobrino

45 La película se estrenó en doble versión: española ( $V a ́$ monos, Bárbara) y catalana (Anem-nos-en, Bàrbara).

46 Hacen el amor delante de una pecera; después, Ana se tumba detrás y al levantarse a medio vestir da la sensación de que sale del agua (literalmente "deja de estar ahogada"). con el Ford Fiesta de Ana para recuperar su Mercedes y cancela la cuenta bancaria común. Ana se reencuentra con su amiga Paula (Julieta Serrano), también separada, y se va a pasar el fin de semana a su casa (sin Bárbara); allí conoce a Iván (Iván Tubau), un joven alternativo (guía turístico) con el que simpatiza. De regreso a la masía se entera de que Remedios ha llamado a Carlos (para recuperar el préstamo que le hizo a su sobrina) y que éste va a mandar a alguien para recoger a la niña. Madre e hija se van a casa de Paula, donde las visita el abogado de Carlos, que amenaza con reclamar la custodia de Bárbara. Ana decide entonces marcharse a Acuamar, allí tiene unos apartamentos que compró con su dinero, y además reside Iván. El conserje llama al marido para pedirle autorización, y luego avisa a un detective para que la espíe. Cuando sospechan que Ana se encuentra con su amante, acuden representantes del juzgado para levantar acta de una demanda de adulterio. Pero Ana está sola y, airada, abandona el apartamento. Al salir se encuentra con el abogado de su marido que la informa de que éste quiere la separación.

Tras recoger a Iván, madre e hija inician el regreso a Barcelona. Pronto el comportamiento del amante (tan similar al del marido y padre) las convence de la necesidad de afrontar su viaje iniciático (la separación) solas, y lo dejan abandonado en una gasolinera. Entonces, Ana y Bárbara se apropian definitivamente de una máquina (el coche), un espacio (la carretera) y un género (la road movie) tradicionalmente masculinos: "If we recall the film's close connection to its socio-historical moment, we can conclude that Ana and Bárbara's journey becomes a metaphor for the women's liberation movement in Spain" ${ }^{47}$. El film no se cierra con la llegada a Barcelona, sino con un plano del Ford Fiesta que conduce Ana (ahora ya en su propio coche) por la carretera (la imagen se congela) (Fig. 5).

A diferencia de las protagonistas de The Rain People, Wanda y Alice Doesn't Live Here Anymore, "películas de carretera" norteamericanas sobre la imposibilidad de la emancipación femenina a las que ya nos hemos referido, en Vámonos, Bárbara, film manifiestamente

\footnotetext{
47 PÉREZ, Jorge, "Spanish Women Behind the Wheel Gendering the Transition to Democracy in Vámonos, Bárbara”, en Revista de Estudios Hispánicos, vol. 42, $\mathrm{n}^{\circ}$ 2, 2008, p. 230.
} 


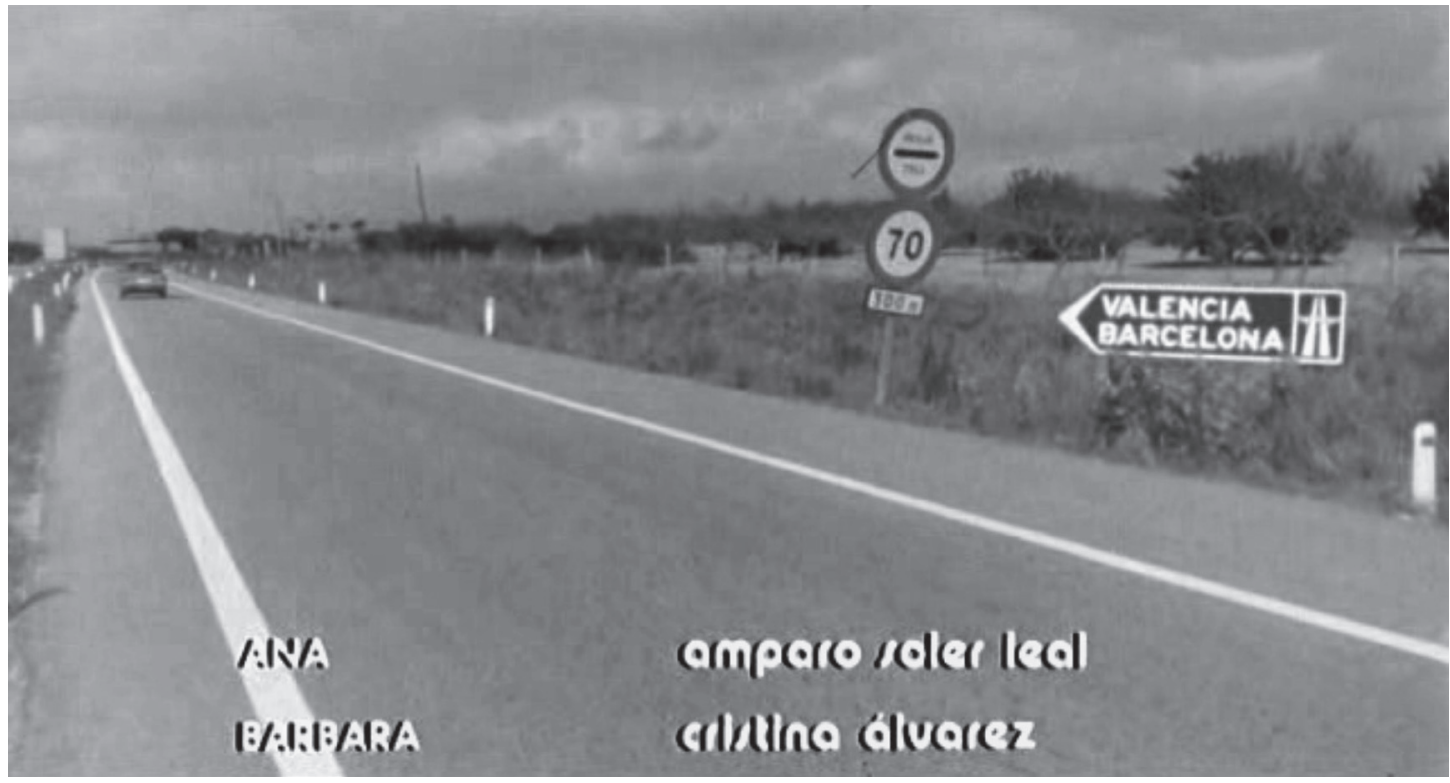

Fig. 5. El Ford Fiesta de Ana camino de Barcelona en el último plano de Vámonos, Bárbara.

feminista, Ana, mujer liberada que trabaja fuera del hogar, consigue desprenderse definitivamente de la dominación masculina (sustituye al Mercedes del marido por su Fiesta, abandona a su nuevo amante Iván) para formar una nueva "pareja" con su hija, compañera y confidente (female buddy), en lo que prefigura la female road movie norteamericana nacida a partir de Thelma \&t Louise.

\section{Conclusiones}

La road movie es un género surgido en EE UU durante el periodo conocido como New Hollywood (1967-1975) que enseguida se difunde por las cinematografías de todo el mundo debido a su capacidad para adaptarse a cualquier cultura sin renunciar a su identidad.
La irrupción de la road movie en el cine español se produce a mediados de los 70 , coincidiendo con los primeros años de la transición a la democracia (1975-1978), la ideologización de los géneros populares, el estreno de Easy Rider en 1975 y la generalización del uso del automóvil. Durante la Transición, el recurso al camino o al viaje en clave metafórica es una constante en muchas manifestaciones escritas $\mathrm{y}$ visuales que en el caso del cine se articuló a través de la poética de la road movie.

Son cuatro los títulos fundacionales del cine español on the road: ¡Jo, papá!, El alijo, El puente y Vámonos, Bárbara. En ellos, diversos personajes (una familia de clase media alta, dos camioneros, un mecánico, una madre y su hija) realizan un viaje trascendente (físico a la vez que interior) por una España en plena transformación pero que todavía conserva las estructuras franquistas. 